\title{
28 Research Square \\ Post Treatment Mastalgia is a Common Complaint But Not an Indication of Recurrence
}

lan Komenaka ( $\sim$ Komenaka@hotmail.com )

Ironwood Cancer and Research Centers https://orcid.org/0000-0002-1479-5639

Chiu-Hsieh Hsu

University of Arizona Medical Center - University Campus: Banner University Medical Center Tucson

Gilbert Ramos

Maricopa Medical Center: Valleywise Health Medical Center

Jesse Nodora

University of California San Diego Moores Cancer Center

Maria Elena Martinez

University of California San Diego Moores Cancer Center

\section{Research Article}

Keywords: post treatment mastalgia, breast cancer, recurrence, breast pain

Posted Date: February 11th, 2022

DOI: https://doi.org/10.21203/rs.3.rs-1336259/v1

License: (c) (1) This work is licensed under a Creative Commons Attribution 4.0 International License.

Read Full License 


\section{Abstract}

Purpose: Post-treatment mastalgia is a common complaint in up to $68 \%$ of patients after treatment. This symptom is worrisome to patients as many believe it is a sign of recurrence. The current study was performed to evaluate if post-treatment mastalgia is associated with breast cancer recurrence.

Methods: Patients included were seen from January 1, 2000 to December 31, 2020. All patients who were treated for breast cancer and then presented with breast pain during follow up were considered to have post-treatment mastalgia. All patients who were diagnosed with a second breast cancer but did not experience post-treatment mastalagia were also evaluated.

Results: 1799 patients had a mean age 52.9 years. $36 \%$ of patients experienced post-treatment mastalgia. Of patients who complained of post-treatment mastalgia, 19 were diagnosed with a chest wall recurrence (CW), ipsilateral breast tumor recurrence (IBTR), or contralateral breast cancer (CBC). 17 of the 19 patients had breast pain after the second diagnosis and treatment were completed. The average duration between their second diagnosis and initial complaint of breast pain was 6.2 years. The two patients who complained of breast pain prior to their second diagnosis did not have mastalgia at the time of their second diagnosis.

Local recurrence or contralateral breast cancer were more common in patients without post treatment mastalgia $(10.1 \%$ vs $0.3 \%, p<0.0001)$ during follow up.

Conclusions: Post treatment mastalgia is not associated with recurrence. Interval or repeat imaging does not appear necessary and instead patient education and reassurance are important in its management.

\section{Introduction}

Breast pain or mastalgia is a very common complaint in outpatient offices and clinics. Approximately 70$80 \%$ of women will experience mastalgia (Joyce, et al. 2014; Ader, et al. 1997a, b). Numerous studies have demonstrated that mastalgia is not a sign or risk factor for breast cancer and instead is attributed to a response in breast tissue to normal physiologic hormones (Jameson, et al 2018; Lobo, et al 2017; Townsend, et al. 2017; Tintinalli, et al. 2020; Kliegman, et al, 2015; Altintas, et al, 2018; Holbrook, et al. 2020; Cho, et al. 2017; Owen, et al. 2019; Chetlen, et al. 2017; Duikm, et al. 1998; Leddy, et al. 2013; Mema, et al. 2019; Fonseca, et al. 2019; Noroozian, et al 2015; Masroor, et al. 2009; Howard, et al. 2012).

After the diagnosis and treatment of breast cancer, breast pain or post treatment mastalgia is similarly common. Several studies have demonstrated a risk of persistent pain after either breast conservation or mastectomy between 20-68\% (Geving Anderson, et al. 2011; Bruce, et al 2012; Bruce, et al. 2014; Schreiber, et al. 2013). This persistent pain after breast cancer treatment is one of the reasons for the COMET (Comparison of Operative versus Monitoring and Endocrine Therapy) trial for low risk ductal carcinoma in situ (Hwang, et al. 2019). This prospective study compares standard of care including operation with radiation therapy as indicated versus endocrine therapy and monitoring with breast 
imaging. Some of the factors associated with chronic or persistent post treatment breast pain include chronic preoperative pain (Bruce, et al 2012) and elevated levels of distress-related psychosocial factors such as anxiety, depression, catastrophizing, and somatization (Bruce, et al. 2014; Schreiber, et al. 2013). In addition, increased sensitivity to mechanical stimulation during quantitative sensory testing (QST) in nonsurgical body areas revealed increased likelihood for persistent post treatment pain (Schreiber, et al. 2013). Breast cancer treatment related factors which may increase risk for post treatment pain include axillary node dissection/clearance (Bruce, et al 2012; Bruce, et al. 2014) and radiation therapy (Geving Anderson, et al. 2011).

No study has yet demonstrated an association between post treatment mastalgia and breast cancer recurrence. Patients, however, fear that mastalgia during breast cancer follow up is a sign of breast cancer recurrence. Despite the lack of an association between mastalgia and breast cancer recurrence, when patients complain of breast pain during follow up visits, clinicians often order breast imaging. When patients have had a benign or stable mammogram within the last 12 months, clinicians will still often repeat another mammogram or order breast ultrasound or breast magnetic resonance imaging.

This study was performed to determine if a complaint of breast pain during breast cancer follow up, or post treatment mastalgia, is a sign of breast cancer recurrence or a second primary breast cancer.

\section{Methods}

This study was conducted at Valleywise/Maricopa Medical Center (VMC) Breast Clinic in Phoenix, Arizona, and reviewed and approved by the institutional review board prior to data collection. All breast cancer patients seen in the Breast Clinic from January 1, 2000 to December 31, 2020, were included. Baseline data for every patient was compiled prospectively, supplemented by retrospective chart review. The data included presenting complaint, history and physical examination including sociodemographic information, medical history, surgical history, and family history, imaging studies, and diagnostic tests. Starting on May 1, 2011 all patients estimated their risk of breast cancer recurrence (Diefenbach, et al. 1993). All records were reviewed to identify diagnoses of breast cancer at the time of initial workup or in subsequent years of available follow up. Breast cancer treatment, follow up, and second cancer diagnoses and treatment were documented.

Determination of the necessity of adjuvant therapy is an individualized patient and physician decision. For purposes of this study, chemotherapy was deemed necessary for triple negative breast cancer and erbB2 (Her2neu) positive breast cancers. In addition, for Luminal breast cancer chemotherapy was deemed necessary for those with a Recurrence Score $>31$ or $>25$ (after 2018) or node positive cancers (Paik, et al. 2006; Sparano, et al. 2018). Radiation therapy was deemed necessary after breast conservation or after mastectomy if the cancer was greater than $5 \mathrm{~cm}, \mathrm{~T} 4$, or node positive (Overgaard M, et al. 1997; Overgaard M, et al. 1999). Endocrine therapy was deemed necessary for any patient with hormone receptor positive breast cancer. Lastly, if there was a documented contraindication for a particular adjuvant therapy then the therapy was considered not necessary. 
After completion of their operation, adjuvant chemotherapy, and radiation therapy for their initial breast cancer, patients who complained of breast pain in either breast were considered to have post treatment mastalgia. Due to the duration of adjuvant targeted (i.e. Herceptin, endocrine therapy, etc.) therapy, patients who had completed surgery, chemotherapy, and radiation therapy, but complained of breast pain while on the targeted therapy were included. For patients who complained of post treatment mastalgia and were diagnosed with a second local breast cancer (chest wall recurrence, ipsilateral breast tumor recurrence, or contralateral breast cancer), the findings on physical examination and breast imaging were documented. In addition, the location of second cancer and the location of the breast pain were documented. The diagnosis, treatment, and follow up for the patients were reviewed. During the same study period, there were 986 patients diagnosed with breast cancer who did not complain of post treatment mastalgia during follow up. Of these patients who were diagnosed with a second breast cancer, their records were reviewed a second time to ensure there was no indication of a complaint of breast pain during follow up.

\section{Statistical Analysis}

Age, education, body mass index, and monthly income were analyzed as continuous variables. Race/ethnicity, employment, insurance status, and screening mammography were analyzed as categorical variables. Health literacy was assessed using the Newest Vital Sign (NVS) (Weiss, et al. 2005; Komenaka, et al. 2014). Patients with NVS 4-6 were categorized as having "adequate health literacy." Patients with NVS 0-3 were considered "low health literacy (Komenaka, et al. 2014)."

Continuous variables were summarized by mean with standard deviation and categorical variables were summarized by frequency and the associated percentage by post treatment mastalgia status. Wilcoxon rank-sum test was performed to compare continuous variables between the two groups. Chi-square test was performed to compare categorical variables between the two groups. Logistic regression was performed to identify variables associated with post treatment mastalgia. Then variables with an unadjusted p-value less than 0.05 were included in the adjusted analysis.

For variables associated with a diagnosis of second cancer, logistic regression was again performed to identify associated variables. The variables with an unadjusted $p$-value less than 0.05 were then included in the adjusted analysis. The adjusted model, however, was likely to be overfitted so the adjusted results were omitted. All statistical tests were two sided and significance levels were set at 0.05 . The statistical methods of this study were performed and reviewed by a biomedical statistician $(\mathrm{CHH})$.

\section{Results}

A total of 1799 patients were seen during the time period. The mean age of the patients was age 52.9 years. Of the patients, 135 presented with or developed metastatic disease prior to their operation. Another 87 patients transferred their care to another facility or moved out of state, whereas 43 other patients either declined an operation or no showed for the procedure. Of the remaining 1534 patients, 
approximately $36 \%$ of patients (548 of 1534) presented with a complaint of post treatment mastalgia at some point during their follow up after breast cancer treatment (Table 1). Many of these patients $(57 \%=$ 310/548) presented more than once with post treatment mastalgia during follow up clinic visits and these patients consistently overestimated their risk of recurrence at $52 \%$. Their estimation of risk was higher than that of patients who complained of post treatment mastalgia at only one visit and higher than those who did not complain of post treatment mastalgia ( $30 \%$ and $19 \%$, respectively, $p<0.01$ ). 
Table 1

Patient sociodemographic information

\begin{tabular}{|c|c|c|c|}
\hline & $\begin{array}{l}\text { Patients with post treatment } \\
\text { mastalgia } \\
(\mathrm{N}=548)\end{array}$ & $\begin{array}{l}\text { All other } \\
\text { patients } \\
(\mathrm{N}=986)\end{array}$ & $\begin{array}{l}\text { p- } \\
\text { value }\end{array}$ \\
\hline Mean age, years (SD) & $51.2(10.5)$ & $53.5(12.1)$ & 0.001 \\
\hline Race/ethnicity & $106(19 \%)$ & $313(32 \%)$ & $<0.001$ \\
\hline Non-Hispanic White & $51(9 \%)$ & $86(9 \%)$ & \\
\hline African American & 357 (65\%) & $522(53 \%)$ & \\
\hline Hispanic & $34(6 \%)$ & $65(7 \%)$ & \\
\hline \multicolumn{4}{|l|}{ Other } \\
\hline Language, English & $231(42 \%)$ & $551(56 \%)$ & $<0.001$ \\
\hline Education, years (SD) & $10.5(4.24)$ & $10.6(4.04)$ & 0.56 \\
\hline 6 or less & $116(22 \%)$ & $172(19 \%)$ & \\
\hline $7-11$ & $128(24 \%)$ & 177 (19\%) & \\
\hline High school/equivalent & $124(23 \%)$ & $203(22 \%)$ & \\
\hline Some college & $91(17 \%)$ & $162(18 \%)$ & \\
\hline College degree & $71(13 \%)$ & $199(22 \%)$ & \\
\hline Missing & 18 & 73 & \\
\hline Adequate Health Literacy & $16 \%(73 / 467)$ & $18 \%(119 / 650)$ & 0.24 \\
\hline Height (m) & $1.59(0.079)$ & $1.59(0.071)$ & 0.99 \\
\hline Weight (kg) & $75.7(16.9)$ & $75.5(17.9)$ & \\
\hline Body mass index in kg/m2 (SD) & $29.8(6.28)$ & $29.8(6.63)$ & \\
\hline Marital status - married & $229(42 \%)$ & $347(35 \%)$ & 0.028 \\
\hline Domestic partner & $30(5 \%)$ & $66(7 \%)$ & \\
\hline Employment, employed & $168(31 \%)$ & $295(30 \%)$ & 0.79 \\
\hline
\end{tabular}

SD - Standard deviation

AHCCCS - Arizona Health Care Cost Containment System 


\begin{tabular}{|llll|}
\hline & $\begin{array}{l}\text { Patients with post treatment } \\
\text { mastalgia } \\
(\mathbf{N}=\mathbf{5 4 8})\end{array}$ & $\begin{array}{l}\text { All other } \\
\text { patients } \\
\mathbf{( N = 9 8 6 )}\end{array}$ & $\begin{array}{c}\text { p- } \\
\text { value }\end{array}$ \\
\hline Insurance status & $22(4 \%)$ & $40(4 \%)$ & $<0.001$ \\
Commercial & $29(5 \%)$ & $93(9 \%)$ & \\
Medicare & $145(26 \%)$ & $323(33 \%)$ & \\
AHCCCS (Medicaid) & $354(65 \%)$ & $530(54 \%)$ & \\
None & & & 0.075 \\
\hline Monthly income \$ (SD) & $1093.70(1175.03)$ & 1021.00 & \\
\hline Undergoing breast screening (40 & $20 \%(92 / 459)$ & $19 \%(161 / 852)$ & 0.61 \\
yr+) & $16 \%(27 / 168)$ & $16 \%(45 / 276)$ & \\
Age 40-49 years & $22 \%(65 / 291)$ & $20 \%(116 / 576)$ & \\
\hline Age 50 years+ & & & \\
\hline SD - Standard deviation & & & \\
\hline AHCCCS - Arizona Health Care Cost Containment System & & \\
\hline
\end{tabular}

Patients who complained of post treatment mastalgia were more likely to be younger, Hispanic, nonEnglish speaking, married or partnered, or uninsured. When surgical treatment was included in the analysis, patients who had bilateral mastectomy or axillary node dissection were more likely to have post treatment mastalgia (Table 2). 
Table 2

Identification of variables associated with post treatment mastalgia

\begin{tabular}{|c|c|c|c|c|c|c|c|c|}
\hline Variable & $\begin{array}{l}\text { Unadj } \\
\text { OR }\end{array}$ & $\begin{array}{l}\text { Lower } \\
95 \% \mathrm{Cl}\end{array}$ & $\begin{array}{l}\text { Upper } \\
95 \% \mathrm{Cl}\end{array}$ & $\begin{array}{l}\mathrm{p}- \\
\text { value }\end{array}$ & $\begin{array}{l}\text { Adj } \\
\text { OR }\end{array}$ & $\begin{array}{l}\text { Lower } \\
95 \% \mathrm{Cl}\end{array}$ & $\begin{array}{l}\text { Upper } \\
95 \% \mathrm{Cl}\end{array}$ & $\begin{array}{l}\mathrm{p}- \\
\text { value }\end{array}$ \\
\hline Age & 0.983 & 0.974 & 0.992 & $<.001$ & 0.992 & 0.977 & 1.009 & 0.36 \\
\hline Hispanic ethnicity & 1.669 & 1.345 & 2.070 & $<001$ & 0.975 & 0.557 & 1.706 & 0.93 \\
\hline English speaking & 0.578 & 0.468 & 0.714 & $\begin{array}{l}<.001 \\
0\end{array}$ & 0.686 & 0.385 & 1.222 & 0.20 \\
\hline Education: 7-11 yrs & 1.072 & 0.773 & 1.488 & 0.68 & & & & \\
\hline Education: 12 yrs & 0.906 & 0.655 & 1.253 & 0.55 & & & & \\
\hline $\begin{array}{l}\text { Education: Some } \\
\text { College }\end{array}$ & 0.833 & 0.588 & 1.180 & 0.3 & & & & \\
\hline $\begin{array}{l}\text { Education: } \\
\text { Bachelor or higher }\end{array}$ & 1.074 & 0.730 & 1.580 & 0.72 & & & & \\
\hline $\begin{array}{l}\text { Adequate health } \\
\text { literacy }\end{array}$ & 0.816 & 0.593 & 1.123 & 0.21 & & & & \\
\hline Married/Partnered & 1.273 & 1.031 & 1.572 & 0.025 & 1.003 & 0.689 & 1.461 & 0.99 \\
\hline Employed & 1.039 & 0.828 & 1.303 & 0.74 & & & & \\
\hline No insurance & 1.549 & 1.252 & 1.918 & $<.001$ & 1.238 & 0.817 & 1.876 & 0.31 \\
\hline $\begin{array}{l}\text { Monthly income } \\
(\$ 1 k)\end{array}$ & 1.054 & 0.963 & 1.153 & 0.25 & & & & \\
\hline $\begin{array}{l}\text { Bilateral } \\
\text { mastectomy }\end{array}$ & 2.022 & 1.352 & 3.025 & $\begin{array}{l}< \\
0.001\end{array}$ & 1.967 & 1.277 & 3.030 & 0.002 \\
\hline $\begin{array}{l}\text { Axillary node } \\
\text { dissecton }\end{array}$ & 0.534 & 0.423 & 0.675 & $\begin{array}{l}<.001 \\
0.00\end{array}$ & 0.670 & 0.470 & 0.956 & 0.027 \\
\hline
\end{tabular}

Of the patients who complained of post treatment mastalgia, 19 were diagnosed with a second local breast cancer: chest wall recurrence (CW), ipsilateral breast tumor recurrence (IBTR), or contralateral breast cancer ( $\mathrm{CBC}$ ) during their follow up. Twelve patients presented with a palpable mass and seven patients presented with abnormal imaging. None of the patients, however, presented with breast pain at the time of their diagnosis of CW/IBTR/CBC (Table 3$)$. Only two patients $(2 / 548=0.3 \%)$ had post treatment mastalgia prior to a second diagnosis and both were contralateral breast cancers. The two patients, however, complained of breast pain 13 years and 3 years prior to their second diagnosis. Both 
patients had normal physical examination, mammogram, and breast ultrasound at the time of their complaint of post treatment mastalgia. Both patients also did not complain of post treatment mastalgia at the time of their second diagnosis. The other 17 of the 19 patients who complained of post treatment mastalgia, complained of breast pain after the second diagnosis and treatment of their CW/IBTR/CBC was completed. The average duration between the diagnosis of their second breast cancer and the initial complaint of breast pain was 6.2 years (range $1-24$ years). 
Table 3

Second breast cancer in patients with post treatment mastalgia

\begin{tabular}{|c|c|c|c|c|c|}
\hline $\begin{array}{l}\text { Patient } \\
\text { Age } \\
\text { (years) }\end{array}$ & Type & $\begin{array}{l}\text { Palpable } \\
\text { Mass/Abnormal } \\
\text { imaging }\end{array}$ & $\begin{array}{l}\text { Date Diagnosis of } \\
\text { CW/IBTR/CBC }\end{array}$ & Date Pain & $\begin{array}{l}\text { Years after } \\
\text { CW/IBTR/CBC } \\
\text { diagnosis }\end{array}$ \\
\hline 58 & $\mathrm{CW}$ & Mass & 2019 & 2020 & 1 \\
\hline 51 & CW & Mass & 2007 & 2014 & 7 \\
\hline 48 & CW & Mass & 2005 & 2006 & 1 \\
\hline 56 & CW & Mass & 1985 & 2007 & 22 \\
\hline 75 & CW & Mass & 1990 & 2014 & 24 \\
\hline 77 & IBTR & Imaging & 2011 & 2015 & 4 \\
\hline 33 & IBTR & Mass & 2004 & 2016 & 12 \\
\hline 59 & IBTR & Mass & 2019 & 2020 & 1 \\
\hline 40 & IBTR & Imaging & 2018 & 2020 & 2 \\
\hline 53 & IBTR & Mass & 2005 & 2010 & 5 \\
\hline 55 & IBTR & Mass & 2004 & 2006 & 2 \\
\hline 45 & IBTR & Mass & 2010 & 2019 & 9 \\
\hline 53 & IBTR & Imaging & 2009 & 2010 & 1 \\
\hline 43 & IBTR & Imaging & 2006 & 2013 & 7 \\
\hline 44 & CBC & Mass & 2010 & $\begin{array}{l}2010 \text { after } \\
\text { treatment }\end{array}$ & 1 \\
\hline 50 & CBC & Imaging & 2011 & 2017 & 6 \\
\hline 58 & CBC & Imaging & 2019 & $\begin{array}{l}2019 \text { after } \\
\text { treatment }\end{array}$ & 1 \\
\hline $\begin{array}{l}\text { Average } \\
52.8\end{array}$ & & & & & 6.2 years \\
\hline 54 & CBC & Imaging & 2020 & 2007 & 13 years prior \\
\hline 47 & $\mathrm{CBC}$ & Mass & 2012 & 2009 & 3 years prior \\
\hline \multicolumn{6}{|c|}{ CW - chest wall recurrence } \\
\hline \multicolumn{6}{|c|}{ IBTR - ipsilateral breast tumor recurrence } \\
\hline $\mathrm{CBC}-\mathrm{CO}$ & ateral & reast cancer & & & \\
\hline
\end{tabular}


Of the 986 who never had a complaint of post treatment mastalgia, $10 \%$ (100 of 986) were diagnosed with a second breast cancer (CW 31, IBTR 48, CBC 21). 64 patients presented with a painless breast mass and one patient presented with skin erythema and thickening without breast pain. The remaining 35 CW/IBTR/CBC were found on routine follow up imaging. Local recurrence or contralateral breast cancer were more common in patients without post treatment mastalgia $(10.1 \%$ vs $0.3 \%, p<0.0001)$ compared to those who had post treatment mastalgia during follow up.

Patients diagnosed with a second breast cancer (CW/IBTR/CBC) were more likely to present with stage II or III breast cancer $(75 \%$ vs $60 \%, p=0.002)$ or with triple negative breast cancer $(30 \%$ vs $20 \%, p=0.011)$ compared to patients who were not diagnosed with a second breast cancer. In addition, patients diagnosed with a second breast cancer (CW/IBTR/CW) were more likely not to have undergone recommended adjuvant chemotherapy, radiation therapy, and endocrine therapy (Table 4). Logistic regression to identify variables associated with a second diagnosis of breast cancer showed that having undergone axillary node dissection and not having recommended Her2 targeted therapy, in addition to the previously mentioned factors, were associated with a diagnosis of a second breast cancer (Table 5). 
Table 4

Patients diagnosed with second cancer and those without second cancer

\begin{tabular}{|c|c|c|c|}
\hline & CW/IBTR/CBC & No second cancer & p-value \\
\hline Mean age, years (SD) & $54.3(13.9)$ & $52.6(11.1)$ & 0.28 \\
\hline Race/ethnicity & $39(32 \%)$ & $345(27 \%)$ & 0.32 \\
\hline Non-Hispanic White & $9(7 \%)$ & $120(9 \%)$ & \\
\hline African American & $64(52 \%)$ & $731(57 \%)$ & \\
\hline Hispanic & $11(9 \%)$ & $84(7 \%)$ & \\
\hline \multicolumn{4}{|l|}{ Other } \\
\hline Education, years (SD) & $11.0(4.65)$ & $10.6(4.04)$ & 0.021 \\
\hline Adequate Health Literacy & $19 / 89(21 \%)$ & $161 / 948(17 \%)$ & 0.36 \\
\hline Body mass index in kg/m2 (SD) & $29.4(6.21)$ & $29.7(6.58)$ & 0.63 \\
\hline Marital status - married & $45(44 \%)$ & $481(43 \%)$ & 0.89 \\
\hline Domestic partner & 9 & 71 & \\
\hline Insurance status & $61(50 \%)$ & 708 (55\%) & 0.26 \\
\hline \multicolumn{4}{|l|}{ None } \\
\hline Undergoing breast screening (40 yr+) & 19/102 (19\%) & $225 / 1107$ (20\%) & 0.62 \\
\hline Preoperative Stage & $11(9 \%)$ & $217(17 \%)$ & 0.002 \\
\hline 0 & $20(16 \%)$ & $292(23 \%)$ & \\
\hline I & $78(63 \%)$ & $619(48 \%)$ & \\
\hline II & $14(12 \%)$ & $152(12 \%)$ & \\
\hline \multicolumn{4}{|l|}{ III } \\
\hline Subtype & $66(60 \%)$ & $674(63 \%)$ & 0.011 \\
\hline Luminal & $14(11 \%)$ & $173(16 \%)$ & \\
\hline ErbB2 (Her2neu) & $32(30 \%)$ & $216(20 \%)$ & \\
\hline \multicolumn{4}{|l|}{ Basal (Triple negative) } \\
\hline \multicolumn{4}{|l|}{ SD - standard deviation } \\
\hline \multicolumn{4}{|l|}{ CW - chest wall recurrence } \\
\hline \multicolumn{4}{|c|}{ IBTR - ipsilateral breast tumor recurrence } \\
\hline $\mathrm{CBC}$ - contralateral breast cancer & & & \\
\hline
\end{tabular}




\begin{tabular}{|llll|}
\hline & CW/IBTR/CBC & No second cancer & p-value \\
\hline Operation & $76(62 \%)$ & $804(63 \%)$ & 0.085 \\
Breast conservation & $41(33 \%)$ & $367(28 \%)$ & 0.005 \\
Mastectomy & $6(5 \%)$ & $109(9 \%)$ & \\
Bilateral mastectomy & $52(42 \%)$ & $377(29 \%)$ & \\
Axillary node dissection & & & \\
\hline Chemotherapy & $62 / 90(69 \%)$ & $642 / 775(83 \%)$ & 0.005 \\
\hline Her2 targeted therapy & $10(83 \%)$ & $145(90 \%)$ & 0.062 \\
\hline Radiation therapy & $64 / 96(67 \%)$ & $824 / 965(85 \%)$ & $<0.001$ \\
\hline Endocrine therapy & $40 / 79(51 \%)$ & $748 / 912(82 \%)$ & $<0.001$ \\
\hline SD - standard deviation & & & \\
\hline CW - chest wall recurrence & & & \\
\hline IBTR - ipsilateral breast tumor recurrence & & \\
\hline CBC - contralateral breast cancer & & \\
\hline
\end{tabular}


Table 5

Identification of variables associated with a diagnosis of second breast cancer

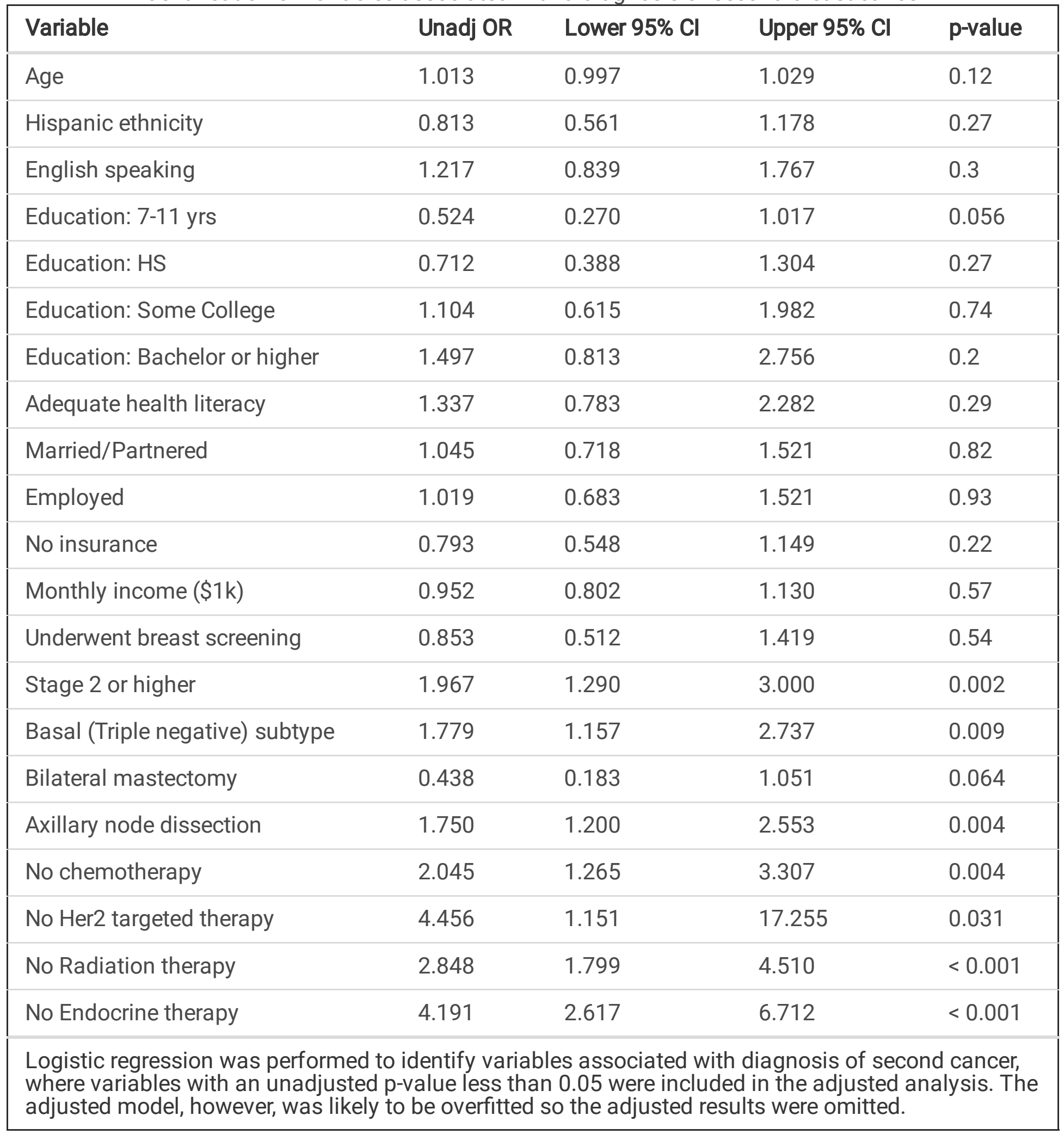

\section{Discussion}

Post treatment mastalgia is a common complaint after breast cancer treatment. The current study found that $36 \%$ of patients complained of post treatment mastalgia. Only two patients $(0.3 \%)$ diagnosed with a 
second breast cancer, however, had ever complained of post treatment mastalgia prior to their second diagnosis. In addition, neither patient had mastalgia at the time of their diagnosis.

Several studies have demonstrated that after treatment of breast cancer, the risk of breast pain or post treatment mastalgia is between 20-68\% (Geving Anderson, et al. 2011; Bruce, et al 2012; Bruce, et al. 2014; Schreiber, et al. 2013). The pain is common and can occur after either breast conservation or mastectomy. The breast pain can persist for 12 years, become a chronic complaint, and sometimes may also be musculoskeletal pain (Bovbjerg, et al. 2019; Lundstedt, et al. 2012; Bell, et al. 2014; Forget, et al. 2020; Macdonald, et al 2005). Treatment related factors include radiation therapy, chemotherapy, younger age at diagnosis, axillary node dissection/clearance and lymphedema (Geving Anderson, et al. 2011; Bruce, et al. 2014; Lundstedt, et al. 2012; Bell, et al. 2014; Peuckmann, et al. 2009; Gärtner, et al. 2009). Bell, et al. reported that while breast cancer treatment contributes to breast pain, it is clear that there is no simple mechanical issue or single treatment factor as the cause (Bell, et al. 2014).

Patients fear that mastalgia is a sign of breast cancer recurrence. Thirteen studies in different populations from several countries have shown no association of mastalgia with an initial diagnosis of breast cancer. Of 13,183 patients only $106(0.8 \%)$ were found to have breast cancer (Altintas, et al, 2018; Holbrook, et al. 2020; Cho, et al. 2017; Owen, et al. 2019; Chetlen, et al. 2017; Duikm, et al. 1998; Leddy, et al. 2013; Mema, et al. 2019; Fonseca, et al. 2019; Noroozian, et al 2015; Masroor, et al. 2009; Howard, et al. 2012). Interestingly, most patients who complained of post treatment mastalgia did not have pain prior to their diagnosis. Of the current patients who complained of post treatment mastalgia, only $2.6 \%$ $(14 / 548)$ had breast pain prior to their initial diagnosis and only two patients had ipsilateral breast pain. Consistent with prior to an initial diagnosis of breast cancer, post treatment mastalgia was not associated with diagnosis of a second breast cancer (CW/IBTR/CBC). Factors that were associated with diagnosis of a second breast cancer included higher stage of cancer and triple negative breast cancer. In addition, as could be expected, not having undergone recommended adjuvant chemotherapy, radiation therapy, and endocrine or targeted therapy were also associated with a second breast cancer diagnosis (Table 4 and 5).

There has been recent substantial growth in neurobiological research on pain and emotion. There is a subcortical circuit that governs defensive responses, and this circuit involves the nonconscious processing of stimuli that underlie emotional states associated with persistent pain. Repeated fear experiences can elicit anticipatory anxiety, thereby contributing to persistent pain (Lumley, et al 2011). The belief that mastalgia indicates cancer recurrence could be considered a continued repeated fear experience.

The majority of patients $(57 \%=310 / 548)$ complained of post treatment mastalgia at more than one follow up clinic visit. These patients substantially overestimated their risk of breast cancer recurrence at $52 \%$. Unfortunately, the belief that mastalgia indicates cancer is common in breast cancer survivors with persistent breast pain. Bovbjerg, et al. found that survivors also had higher levels of general anxiety, pain catastrophizing, and worry (Bovbjerg, et al. 2019). One patient in the current study complained of breast 
pain at seven consecutive follow up visits over a 3 year period including several Emergency Department visits. Despite undergoing standard follow up imaging and being reassured during each visit, the patient insisted that the post treatment mastalgia was a sign that she had breast cancer recurrence. The patient did not have a second breast cancer and was eventually seen by a psychiatrist and diagnosed with illness anxiety disorder for which she started cognitive behavioral therapy (Scarella, et al 2019). Bovbjerg, et al. similarly concluded that perceived risk of breast cancer and worry that pain may indicate cancer as important targets for intervention (Bovbjerg, et al 2019; Porter, et al. 2011). Augmentation of positive emotional states or relief of fear and anxiety generally have been found to reduce pain (Lumley, et al. 2011; Franklin 1998). A study by Bruce, et al. found that psychological robustness or dispositional optimism and positive affect may also have a favorable effect on post-operative breast pain severity (22). Pain is a subjective, complicated patient-reported phenomenon likely multifactorial and involving preoperative patient psychological factors (Bruce, et al. 2012; Schreiber, et al. 2013; Macdonald, et al. 2005; Törer, et al. 2010). Breast cancer patients experience anticipatory psychological distress prior to their diagnosis of breast cancer and prior to their cancer operation (Schnur, et al. 2008; Montgomery, et al 2010). Other studies have found that patients with greater preoperative emotional distress, depression and anxiety scores have significantly more clinically meaningful and chronic postoperative pain (Bruce, et al. 2014; Törer, et al. 2010; Katz, et al. 2005). Therefore it is possible that patients with more fear and worry about their prognosis may have more post treatment pain.

Schreiber, et al. found that patients with persistent postmastectomy pain were more likely to catastrophize in response to pain (Schreiber, et al. 2013). This study provides reassurance that post treatment mastalgia is not associated with breast cancer recurrence. Worry that breast pain indicates cancer is a common belief and source of distress for patients. Since post treatment mastalgia can become a chronic problem and a factor which lowers quality of life for patients (Macdonald, et al. 2005; Peuckmann, et al 2009), the current findings may help lessen worry about pain as a patient-reported outcome.

The findings of the current study that post treatment mastalgia is not a sign of breast cancer recurrence is also relevant because it makes interval mammography and other imaging unnecessary. It is particularly important to avoid unnecessary mammography in breast cancer survivors with persistent breast pain. A study by Shelby, et al found that breast pain and mammography related anxiety were associated with not returning for a mammogram (Shelby, et al 2012). Therefore post treatment mastalgia could inadvertently contribute to decreased compliance with recommended imaging during follow up.

One limitation of this study is that it is a retrospective review from one institution. The retrospective design of the current study, however, did allow review of patients diagnosed with a second breast cancer who presented with all other complaints to ensure that no patients who complained of post treatment mastalgia were missed.

Post treatment mastalgia is a common complaint after breast cancer treatment. Many patients fear that this symptom indicates cancer recurrence. This study demonstrated that post treatment mastalgia is not 
a sign or risk factor for recurrent breast cancer. Since there is no evidence of increased risk for recurrent cancer, additional imaging can be avoided and prevent low-value care and instead preserve healthcare resources. Unnecessary breast imaging may also reinforce fearful behavior and exacerbate the belief in patients that "something should always be done (Kool, et al. 2020)." In addition, avoidance of unnecessary imaging can lessen anticipatory anxiety, thereby lowering the likelihood of persistent pain (Lumley, et al. 2011). Reassurance is critical to the management of breast pain, not the unnecessary use of healthcare resources.

\section{Declarations}

\section{Funding:}

The authors did not receive support from any organization for the submitted work.

\section{Conflicts of interest/Competing interests:}

The authors have no relevant financial or non-financial interests to disclose.

The authors have no conflicts of interest to declare that are relevant to the content of this article.

All authors certify that they have no affiliations with or involvement in any organization or entity with any financial interest or non-financial interest in the subject matter or materials discussed in this manuscript.

The authors have no financial or proprietary interests in any material discussed in this article.

\section{Author Contributions}

All authors contributed to the study conception and design. Material preparation, data collection and analysis were performed by lan Komenaka and Chiu-Hsieh Hsu. The first draft of the manuscript was written by lan Komenaka and all authors commented on previous versions of the manuscript. All authors read and approved the final manuscript.

\section{References}

1. Ader DN, Browne MW (1997) Prevalence and impact of cyclic mastalgia in a United States clinicbased sample. Am J Obstet Gynecol 177(1):126-132

2. Ader DN, Shriver CD (1997) Cyclical mastalgia: prevalence and impact in an outpatient breast clinic sample. J Am Coll Surg 185(5):466-470

3. Altıntas Y, Bayrak M (2018) Evaluation of 1294 Female Patients with Breast Pain: A Retrospective Study. Adv Ther 35(9):1411-1419

4. Bell RJ, Robinson PJ, Nazeem F et al (2014) Persistent breast pain 5 years after treatment of invasive breast cancer is largely unexplained by factors associated with treatment. J Cancer Surviv 8(1):1-8 
5. Bovbjerg DH, Keefe FJ, Soo MS et al (2019) Persistent breast pain in post-surgery breast cancer survivors and women with no history of breast surgery or cancer: associations with pain catastrophizing, perceived breast cancer risk, breast cancer worry, and emotional distress. Acta Oncol 58(5):763-768

6. Bruce J, Thornton AJ, Scott NW et al (2012) Chronic preoperative pain and psychological robustness predict acute postoperative pain outcomes after surgery for breast cancer. $\mathrm{Br} \mathrm{J}$ Cancer 107(6):937946

7. Bruce J, Thornton AJ, Powell R, Recovery Study Group et al (2014) Psychological, surgical, and sociodemographic predictors of pain outcomes after breast cancer surgery: a population-based cohort study. Pain 155(2):232-243

8. Chetlen AL, Kapoor MM, Watts MR (2017) Mastalgia: Imaging Work-up Appropriateness. Acad Radiol 24(3):345-349

9. Cho MW, Grimm LJ, Johnson KS (2017) Focal Breast Pain: Does Breast Density Affect the Need for Ultrasound? Acad Radiol 24(1):53-59

10. Diefenbach MA, Weinstein ND, O'Reilly J (1993) Scales for assessing perceptions of health hazard susceptibility. Health Educ Res 8(2):181-192

11. Duijm LE, Guit GL, Hendriks JH, Zaat JO, Mali WP (1998) Value of breast imaging in women with painful breasts: observational follow up study. BMJ 317(7171):1492-1495

12. Fonseca M, Lamb LR, Verma R, Ogunkinle O, Seely JM (2019) Breast pain and cancer: should we continue to work-up isolated breast pain? Breast Cancer Res Treat 177(3):619-627

13. Forget P, Sitter TM, Hollick RJ, The KBCt Group et al (2020) Characterization of Preoperative, Postsurgical, Acute and Chronic Pain in High Risk Breast Cancer Patients. J Clin Med 9(12):3831

14. Franklin KB (1998) Analgesia and abuse potential: an accidental association or a common substrate? Pharmacol Biochem Behav 59(4):993-1002

15. Gärtner R, Jensen MB, Nielsen J, Ewertz M, Kroman N, Kehlet H (2009) Prevalence of and factors associated with persistent pain following breast cancer surgery. JAMA 302(18):1985-1992

16. Geving Andersen K, Kehlet H (2011) Persistent pain after breast cancer treatment: a critical review of risk factors and strategies for prevention. J Pain 12(7):725-746

17. Holbrook Al (2020) Breast Pain, A Common Grievance: Guidance to Radiologists. AJR Am J Roentgenol 214(2):259-264

18. Howard MB, Battaglia T, Prout M, Freund K (2012) The effect of imaging on the clinical management of breast pain. J Gen Intern Med 27(7):817-824

19. Hwang ES, Hyslop T, Lynch T et al (2019) The COMET (Comparison of Operative versus Monitoring and Endocrine Therapy) trial: a phase III randomised controlled clinical trial for low-risk ductal carcinoma in situ (DCIS). BMJ Open 9(3):e026797

20. Jameson JL, Fauci AS, Hauser SL, Longo DL, Loscalzo J (eds) (2018) Harrison's Principles of Internal Medicine, 20th edn. MCGraw-Hill Education, New York, NY 
21. Joyce DP, Alamiri J, Lowery AJ et al (2014) Breast clinic referrals: can mastalgia be managed in primary care? Ir J Med Sci 183(4):639-642

22. Kliegman RM, Stanton BF, St Gerne JW, Shchor NF (eds) (2015) Nelson Textbook of Pediatrics. Elsevier, Philadelphia, PA

23. Katz J, Poleshuck EL, Andrus CH et al (2005) Risk factors for acute pain and its persistence following breast cancer surgery. Pain 119(1-3):16-25

24. Komenaka IK, Nodora JN, Machado L et al (2014) Health literacy assessment and patient satisfaction in surgical practice. Surgery 155(3):374-383

25. Kool RB, Verkerk EW, Winnemuller LJ et al (2020) Identifying and de-implementing low-value care in primary care: the GP's perspective-a cross-sectional survey. BMJ Open 10(6):e037019

26. Leddy R, Irshad A, Zerwas E et al (2013) Role of breast ultrasound and mammography in evaluating patients presenting with focal breast pain in the absence of a palpable lump. Breast $J$ 19(6):582589

27. Lobo RA, Gershenson DM, Lentz GM, Valea FA (eds) (2017) Comprehensive Gynecology, 7th edn. Elsevier, Philadelphia, PA

28. Lumley MA, Cohen JL, Borszcz GS et al (2011) Pain and emotion: a biopsychosocial review of recent research. J Clin Psychol 67(9):942-968

29. Lundstedt D, Gustafsson M, Steineck $G$ et al (2012) Risk factors of developing long-lasting breast pain after breast cancer radiotherapy. Int J Radiat Oncol Biol Phys 83(1):71-78

30. Macdonald L, Bruce J, Scott NW, Smith WC, Chambers WA (2005) Long-term follow-up of breast cancer survivors with post-mastectomy pain syndrome. Br J Cancer 92(2):225-230

31. Masroor I, Afzal S, Sakhawat S, Khan N, Beg MA, Kawal D (2009) Negative predictive value of mammography and sonography in mastalgia with negative physical findings. J Pak Med Assoc 59(9):598-601

32. Mema E, Cho E, Ryu YK et al (2019) In the Setting of Negative Mammogram, Is Additional Breast Ultrasound Necessary for Evaluation of Breast Pain? Curr Probl Diagn Radiol 48(2):117-120

33. Montgomery GH, Schnur JB, Erblich J, Diefenbach MA, Bovbjerg DH (2010) Presurgery psychological factors predict pain, nausea, and fatigue one week after breast cancer surgery. J Pain Symptom Manage 39(6):1043-1052

34. Noroozian M, Stein LF, Gaetke-Udager K, Helvie MA (2015) Long-term clinical outcomes in women with breast pain in the absence of additional clinical findings: mammography remains indicated. Breast Cancer Res Treat 149(2):417-424

35. Overgaard M, Hansen PS, Overgaard J et al (1997) Postoperative radiotherapy in high-risk premenopausal women with breast cancer who receive adjuvant chemotherapy. Danish Breast Cancer Cooperative Group 82b Trial. N Engl J Med 337(14):949-955

36. Overgaard M, Jensen MB, Overgaard J et al (1999) Postoperative radiotherapy in high-risk postmenopausal breast-cancer patients given adjuvant tamoxifen: Danish Breast Cancer 
Cooperative Group DBCG 82c randomised trial. Lancet 353(9165):1641-1648

37. Owen WA, Brazeal HA, Shaw HL, Lee MV, Appleton CM, Holley SO (2019) Focal breast pain: imaging evaluation and outcomes. Clin Imaging 55:148-155

38. Paik S, Tang G, Shak S et al (2006) Gene expression and benefit of chemotherapy in women with node-negative, estrogen receptor-positive breast cancer. J Clin Oncol 24(23):3726-3734

39. Peuckmann V, Ekholm O, Rasmussen NK et al (2009) Chronic pain and other sequelae in long-term breast cancer survivors: nationwide survey in Denmark. Eur J Pain 13(5):478-485

40. Porter LS, Keefe FJ (2011) Psychosocial issues in cancer pain. Curr Pain Headache Rep 15(4):263270

41. Scarella TM, Boland RJ, Barsky AJ (2019) Illness Anxiety Disorder: Psychopathology, Epidemiology, Clinical Characteristics, and Treatment. Psychosom Med 81(5):398-407

42. Schnur JB, Montgomery GH, Hallquist MN et al (2008) Anticipatory psychological distress in women scheduled for diagnostic and curative breast cancer surgery. Int J Behav Med 15(1):21-28

43. Schreiber KL, Martel MO, Shnol $\mathrm{H}$ et al (2013) Persistent pain in postmastectomy patients: comparison of psychophysical, medical, surgical, and psychosocial characteristics between patients with and without pain. Pain 154(5):660-668

44. Shelby RA, Scipio CD, Somers TJ, Soo MS, Weinfurt KP, Keefe FJ (2012) Prospective study of factors predicting adherence to surveillance mammography in women treated for breast cancer. $\mathrm{J}$ Clin Oncol 30(8):813-819

45. Sparano JA, Gray RJ, Makower DF et al (2018) Adjuvant Chemotherapy Guided by a 21-Gene Expression Assay in Breast Cancer. N Engl J Med 379(2):111-121

46. Tintinalli JE, Editor in Chief (2020) Tintinalli's Emergency Medicine, 9th edn. McGraw-Hill Education, New York, NY

47. Törer N, Nursal TZ, Calişkan K et al (2010) The effect of the psychological status of breast cancer patients on the short-term clinical outcome after mastectomy. Acta Chir Belg 110(4):467-470

48. Townsend CM, Beauchamp RD, Evers BM (eds) (2017) Sabiston Textbook of Surgery, 20th edn. Elsevier, Philadelphia, PA

49. Weiss BD, Mays MZ, Martz W et al (2005) Quick assessment of literacy in primary care: the newest vital sign. Ann Fam Med 3(6):514-522 